\title{
Study on Quality Evaluation of Taiwan's B\&B Based on Content Analysis Method and Its Implications
}

\author{
Chunxia Tan \\ Jinhua Politechnic, No. 1188 Wuzhou Street, Jinhua 321000, Zhejiang, China
}

Corresponding Author Email: jhctcx@ 126.com

https://doi.org/10.18280/ijsdp.160210

Received: 3 February 2021

Accepted: 9 April 2021

\section{Keywords:}

Taiwan $B \& B$ quality, evaluation system, content analysis method

\begin{abstract}
Taiwan has been nearly 40 years of history in developing B\&B, and has accumulated rich experience in $\mathrm{B} \& \mathrm{~B}$ development and management. While $\mathrm{B} \& \mathrm{~B}$ history is much shorter in mainland China, there is a gap of industry matureness between two sides. Therefore, it is of great practical significance for the development of $\mathrm{B} \& \mathrm{~B}$ in mainland China to systematically discuss the quality of B\&B in Taiwan. This study extracted 24 B\&B cases in Taiwan from Agoda website, based on stratified sampling method, and classified and assigned values according to the quality evaluation index and coding standard with content analysis method. Finally, the paper obtained the key factors of the quality of the B\&B based on the evaluation of indicators at all levels, and got the correlation analysis results: cost performance and fitment time are positively correlated to the quality of the $\mathrm{B} \& \mathrm{~B}$ while guestroom number is negatively correlated to the quality of the B\&B.
\end{abstract}

\section{INTRODUCTION}

Taiwan's B\&B industry originated in the 1980s, it gradually becoming an influential industry since there was the serious shortage of accommodation facilities in the Kenting National Park, Alishan, Xitou, etc., thus local farmers provided their own houses for rent [1]. At the beginning of the 21 st century, Taiwan formed "Administrative Measures for B\&B in Taiwan" which systematically clarified the qualifications and requirements of $\mathrm{B} \& \mathrm{~B}$, and played an important role in guiding, regulating and developing B\&B industry (Tourism Bureau, Republic of China (Taiwan), 2003). Taiwan has been developing B\&B for nearly 40 years and is presently the area with highest density of $\mathrm{B} \& \mathrm{~B}$ in the world. According to "the Report of B\&B Development in Taiwan, 2017”, there were altogether 8386 B\&Bs which made 3.62 billion Yuan RMB by the end of 2017 and $88 \%$ of independent tourists from mainland of China prefer to stay in a B\&B while visiting Taiwan. Taiwan's B\&B tourism industry has already become the shining point to attract tourists. It is the landmark product of in-depth tourism in Taiwan, China. On the other hand, considering $\mathrm{B} \& \mathrm{~B}$ in mainland China started from the inns in Lijiang, the development process is just over ten years [2]. Because of low threshold, B\&B industry in mainland of China has been exploded by supportive policies issued by the government since 2015. According to "the Report of B\&B Development in China, 2017", the total number of B\&Bs in mainland of China has already exceeded 200 thousand by the end of 2017 with year-on-year growth of $300 \%$. Out-of-order development led to the issues of product homogeneity, low quality and low occupancy rate. Therefore, the experience of development, management and operation of Taiwan's B\&B has a positive reference for present $B \& B s$ in mainland of China.
The author collected data to systematically analyze and evaluate the quality of $B \& B$ in Taiwan based on the B\&B feedbacks on the websites, and put forward some thoughts on improving the quality of $\mathrm{B} \& \mathrm{~B}$ in mainland of China.

\section{LITERATURE REVIEW}

\subsection{Comparison of definitions of $B \& B$ between Taiwan and mainland China}

According to the "Administrative Measures for B\&B in Taiwan", B\&B refers to the vacant rooms in self-used residence which are used to provide tourists with accommodation for rural life and operate as a family sideline, and combing local humanities, natural landscapes, ecology, environmental resources, and agricultural, forestry, fishery and animal husbandry production activities.

In 2019, the Ministry of Culture and Tourism of China issued "Basic Requirements and Evaluation for Homestay Inn" and defined B\&B as "Small accommodation with structure less than 4 layers and total area less than 800 square meters, established with idle resources, where owners provide service and experience of local nature, culture and production and life style to tourists.

Compare these two definitions, we can conclude B\&B refers similar business in both Taiwan and mainland of China: Small family accommodation business providing tourists with life style experience.

\subsection{Summary of research on B\&B quality in Taiwan}

Research on the quality of Taiwan's B\&B can be divided into two types. 
Firstly, perception of service quality. Taiwan scholars such as Guo Chunmin used questionnaire surveys and statistical analysis to explore the difference between $\mathrm{B} \& \mathrm{~B}$ operators and consumers about the perception of service quality [3]. Su Limin and Wang Chaohong summarized the five key factors that influence consumers select a B\&B: "hardware facilities", "service experience", "brand loyalty", "sensory experience" and "price factor", and came up with the advantages and disadvantages of service quality in B\&B [4]. Zhuang Wanlin and Lin Zongliang indicated that tourists from different backgrounds have differences in the satisfaction of service quality [5].

Secondly, the relationship between service quality and other factors. For example, the relationship between service quality and satisfaction [6]; the relationship between service quality and recreational experience [7]; the relationship among service quality, shopping value and behavior intention [8]. Most of studies used questionnaire survey data, applying structural equation models or hierarchical linear models to explore the connection between B\&B service quality and other factors.

However, whether studying the B\&B service quality cognitive or the relationship between $B \& B$ service quality and other factors, most of them are based on questionnaire data. Since B\&B websites are rapidly developing, applying online feedbacks to conduct in-depth research on B\&B quality will further improve the quality research system of B\&B.

\subsection{The Summary of research on personalized service of B\&B in Taiwan}

Personalized feature of $\mathrm{B} \& \mathrm{~B}$ is the key factor and strategy to its success in Taiwan. The core is to provide innovative products of differentiated and themed services relying on current resources to a niche market, through which its own value forms [9]. The personalized experience obtained in different B\&Bs is usually rooted in the owner's different understanding of life. The service style, decoration style and garden design of a B\&B reflects owner's life philosophy and the theme of a B\&B, such as rural life, foreign style, Taiwan aborigine's life, family style, agricultural life, usually reflects the owner's life experience [10]. The personalized features of $\mathrm{B} \& \mathrm{Bs}$ in Taiwan are also benefit from its rich aborigine culture and Taiwan's unique aesthetics of life. B\&B product diversification meets the requirement of diversified choices of consumers [11].

\section{METHODOLOGY}

\subsection{Research method}

This research mainly adopts the online text analysis method, which is derived from the text analysis method. Text analysis is a research method that objectively, systematically and quantitatively analyzes non-quantitative content materials such as text and images, and ultimately reveals the nature of the content with quantitative results to achieve in-depth understanding [12]. With the development of internet, people are getting used to book accommodation products and share experience online. Therefore, the online review data is believed to be important resource of tourism information [13]. Compared with questionnaire research, online review data has the advantage of authenticity and objectivity. With the development of web crawler technology, more comprehensive and complete online review data can be easily obtained. Therefore, using online review data for text analysis, known as online text analysis, is getting more and more popular with foreign researchers. This article mainly uses the online text analysis method to encode the feedbacks from B\&B guests, and applies SPSS13.0 for statistical analysis.

\subsection{Sample}

Agoda has been selected as the sample website. Because the scope of services on Agoda are mainly in Southeast Asia. Agoda, founded in Asia, is a professional online travel service company that mainly provides lodging reservation services in China, Japan, South Korea, and Southeast Asia. Just in Asia, Agoda provides reservation services for more than 69,000 lodging properties. Then, Agoda have complete types of service, visitors can easily find most popular tourist attractions, emerging tourist cities, and even little-known destinations on Agoda. Furthermore, Agoda's customers are widely distributed in Southeast Asia, including local Taiwan market, Hong Kong market, and mainland of China market [14].

Selecting the sample B\&B mainly adopts the stratified sampling method. According to the statistics of the Taiwan Tourism Bureau in 2017 Hualian County, Yilan County, Taitung County, Nantou County, Pingtung County, and Penghu County ranks the top six of total number of B\&B, and each of them are more than 500. Therefore, this article selects these six counties, and select $4 \mathrm{~B} \& \mathrm{~B}$ from each county. The time range of sample selection is from December 2019 to December 2020. According to the number of reviews and rankings on Agoda, a total of 24 homestays were finally selected. See Table 1 for details.

Table 1. Sample distribution and comment extraction

\begin{tabular}{|c|c|c|c|c|}
\hline County & B\&B & $\begin{array}{l}\text { Eft. } \\
\text { rev. }\end{array}$ & $\begin{array}{l}\text { Ttl. } \\
\text { rev. }\end{array}$ & Pct. \\
\hline \multirow[t]{4}{*}{ Hualian } & Ediman B\&B & 24 & 100 & 16.4 \\
\hline & Fun House & 30 & & \\
\hline & $\begin{array}{c}\text { Impression Classics } \\
\text { B\&B }\end{array}$ & 20 & & \\
\hline & Fazhana Hotel B\&B & 26 & & \\
\hline \multirow[t]{4}{*}{ Yilan } & My Dream Castle & 30 & 108 & 17.7 \\
\hline & $\begin{array}{l}\text { Fairytale Hot Spring } \\
\text { Hotel }\end{array}$ & 40 & & \\
\hline & Village B\&B & 22 & & \\
\hline & Hangkhau Hotel & 16 & & \\
\hline \multirow[t]{4}{*}{ Taitung } & Mini Gardens & 26 & 96 & 15.7 \\
\hline & Sanasai Inn & 26 & & \\
\hline & Master Bear Resort & 20 & & \\
\hline & Yipin Garden B\&B & 24 & & \\
\hline \multirow[t]{4}{*}{ Nantou } & Sun Moon Lake Hostel & 42 & 112 & 18.4 \\
\hline & Juby Landscape Villa & 26 & & \\
\hline & Spring Ground Hotel & 26 & & \\
\hline & Qinhai Hotels & 18 & & \\
\hline \multirow[t]{4}{*}{ Pingtung } & Dolphin Castle & 16 & 88 & 14.4 \\
\hline & $22 \mathrm{~B} \& \mathrm{~B}$ & 28 & & \\
\hline & Zhuji Hostel & 24 & & \\
\hline & Wei Feng Motel & 20 & & \\
\hline \multirow[t]{4}{*}{ Penghu } & Sea Residence & 16 & 106 & 17.4 \\
\hline & Spring Villa Sanduo & 38 & & \\
\hline & 123 V-Stone B\&B & 30 & & \\
\hline & Green Hotel & 22 & & \\
\hline Total & $24 \mathrm{~B} \& \mathrm{~B}$ & 610 & 610 & 100 \\
\hline
\end{tabular}




\subsection{Establishment of Taiwan B\&B Quality Evaluation System}

With reference to the hotel and short-term rental service quality text analysis system, and combined the actual situation of this research, the author indicated the evaluation index of Taiwan B\&B's quality through the trial analysis of 48 samples (two pieces of review data from each selected B\&B), and finally determined the evaluation index system of this research. The evaluation indicators and coding standards are shown in Table 2.

Table 2. Quality evaluation index and coding standard

\begin{tabular}{cc}
\hline Code & Indicators \\
\hline A & GENERAL EVALUATION \\
A1 & General Comprehensive Evaluation \\
A2 & General Service Evaluation \\
A3 & General Facility Evaluation \\
A4 & General Hygienic Evaluation \\
A5 & General Ambience Evaluation \\
B & BUSINESS SITE \\
B1 & Geographical Location
\end{tabular}

B11: Surroundings; B12: Convenient transportation; B13: Distance from tourist attractions/city center; B14: Parking lots.

B2

Fitment

B21: Fitment time; B22: Style Security

B3

C

$\mathrm{C} 1$

$\mathrm{C} 2$

D

D1

D2

D3

B31: Neighbors' attitude; B32: Security management.

\section{FACILITIES}

Guestroom

C11: Area; C12: Cleanness; C13: Room types; C14: Decoration; C15: Theme; C16: Sound insulation. Bed

C21: Comfortableness; C22: Size;

C23: Bed amenities.

Bathroom

C31: Cleanness; C32: Space; C33: Facilities;

C34: Bath amenities.

Electrical Equipment

C41: Completeness; C42: Performance;

C43 Intelligent.

Entertainment

C51: Tea bar; C52: Junior rides,

C53: Swimming pool, SPA etc.,

SERVICE

F\&B Service

D11: Breakfast; D12: F\&B flavor; D13: Free meal

Personalized Service

D21: Car rental service; D22: Laundry service

D23: Pick-up Service; D24: Print service;

D25: Photography; D26: Gift. Tourism Service

D31: Tourism activities arrangement;

D32: Valet booking; D33: Free map;

D34: Guide service

Marketing

Cost Performance

E2 Propaganda matches reality

\section{Note:}

1. There are obvious "excellent", "good", "normal", "poor" and "very bad" in the coding.

2. Estimating and classifying other words appearing in reviews:

(1) Classified as "excellent ": appearing adverbs of degree "very/ awfully/

super/ particularly + positive words", such as very/ awfully/ super/ particularly (satisfied, great, praise, etc.)

(2) Classified as "good": appearing "good", "well", "great"; there are degree adverbs "quite/comparatively + positive words", such as quite/comparatively (good, clean, satisfaction, etc.); Adverbs of degree are not used, but used separate words of praise/positive meaning, such as large, convenient, clean, etc.

(3) Classified as "normal": appearing adverbs of degree "a bit/some + words with negative meaning", such as a bit (noisy, bad, and dirty); appearing "to be improved/need to complete/not bad".

(4) Classified as "poor": Adverbs of degree are not used, but used separate negative/derogatory words, such as dirty, inconvenient, not easy to use, etc.

(5) Classified as "very bad": Adverbs of degree of appearance very/awfully/super/particularly + words with negative meaning, such as very/awfully/super/particularly (noisy, dirty, small, cold, etc.)

\subsection{Data collection and processing}

The collected data is assigned by the Likert scale method, 1-5 represent the five levels of B\&B quality: very bad, poor, normal, good, and excellent. The evaluation of reviews is performed by a scoring team leader and two raters according to the coding standards. If the consistency of the scoring results reaches or exceeds $75 \%$, it will be adopted; otherwise, it will be re-scored. If the consistency has not reached the standard all through, the scoring result of team leader will be applied. The final result used SPSS 18.0 statistical software to analyze the collected data.

\section{DATA ANALYSIS}

\subsection{Analysis of the overall situation of the sample}

This survey collected a total of 610 reviews. The overall situation of the review samples is shown in Table 3. Among the 610 review samples, the price range around 1000-3000 yuan $(60.5 \%)$, the guestroom numbers are $1-15$ rooms $(87.8 \%)$, and latest refurbished time is 2011-2015 (64.1\%) have higher percentage.

Table 3. Sample analysis

\begin{tabular}{ccc}
\hline Variables & Category & Distribution \\
\hline & below 1000 yuan & $2.7 \%$ \\
$1000-2000$ yuan & $40.0 \%$ \\
Price & $2001-3000$ yuan & $20.5 \%$ \\
& 3001-4000 yuan & $14.5 \%$ \\
& $4001-5000$ yuan & $11.8 \%$ \\
& above 5000 yuan & $10.5 \%$ \\
Guestroom & $1-5$ & $33.2 \%$ \\
number & $6-10$ & $23.2 \%$ \\
& $11-15$ & $31.4 \%$ \\
Latest & $16-20$ & $2.7 \%$ \\
refurbished & above 20 & $9.5 \%$ \\
time & before 2010 & $29.6 \%$ \\
& $2011-201$ & $14.4 \%$ \\
& $2014-2015$ & $49.7 \%$ \\
\hline
\end{tabular}

\subsection{High-frequency vocabulary analysis}

Key words of the online review data were analyzed with SPSS 18.0 and all the words appeared over 20 times (as shown in Table 4) for the research on tourists' perception of quality of Taiwan B\&B. The result of high-frequency vocabulary analysis shows tourists paid most attention to transportation, room facility and hygiene, fitness time and style, service and price. Extracted vocabulary such as surroundings, convenient transportation, distance from tourist attractions/city center, etc. reflect tourist's perception of accessibility of B\&B; cleanness, completeness, area, sound insulation, performance, comfortableness, bathroom facilities, etc. reflect tourist's 
perception of qualities of B\&B facilities and hygiene; style and fitness time reflect tourist's perception of decoration; breakfast service, flavor, tourism activity arrangement, free meal, pickup service , etc. reflect tourist's perception of service quality; price reflects tourist's perception of cost performance.

Table 4. High-frequency vocabulary extracted from research samples

\begin{tabular}{ccc}
\hline No & High-frequency vocabulary & Frequency \\
\hline 1 & convenient transport & 97 \\
2 & cleanness & 96 \\
3 & distance from tourist attractions/city center & 83 \\
4 & breakfast service & 80 \\
5 & surroundings & 69 \\
6 & completeness & 67 \\
7 & style & 61 \\
8 & area & 50 \\
9 & fitness time & 47 \\
10 & tourism activity arrangement & 47 \\
11 & price & 39 \\
12 & sound insulation & 36 \\
13 & flavor & 33 \\
14 & Performance & 31 \\
15 & comfortableness & 28 \\
16 & Bathroom facility & 22 \\
17 & Free meal & 22 \\
18 & Pick-up service & 20 \\
\hline
\end{tabular}

\subsection{Descriptive analysis}

Guests' attention and satisfaction can be known from their scores and the mentioned frequency of indicators. The higher the mentioned frequency, the higher the attention of indicators; the higher the score, the higher the satisfaction of indicators.

\subsubsection{Overall evaluation}

The data shows that $48.6 \%$ of the reviews are concentrated on "general service evaluation", $21.5 \%$ of the reviews are focus on "general ambience evaluation", while "general hygienic evaluation" and "general facility evaluation" are just account for $11.3 \%$ and $6.2 \%$, respectively (See Table 5).

The average score of the "general comprehensive evaluation" of Taiwan B\&B is 4.23, and the average range of other factors' general evaluation is 3.82-4.55 (See Table 5). Among that, "general service evaluation" (4.55) has the highest average score, the main keywords are "kind", "enthusiastic", "nice", "friendly", "humane", "intimate", "polite", "patient", etc. Followed by "general ambience evaluation" (4.29), the main keywords are "scenery", "feeling at home", "quiet", "isolate" ". The third is "general hygienic evaluation" (4.25), the main keywords are "clean", "tidy" and "odor". While "general facility evaluation" (3.82) is the lowest, and the main keywords are "complete" and "functional".

Table 5. Score of "General Evaluation" index

\begin{tabular}{cccccc}
\hline Items & GCE & GSE & GAE & GHE & GFE \\
Percentage & 12.4 & 48.6 & 21.5 & 11.3 & 6.2 \\
Average & 4.23 & 4.55 & 4.29 & 4.25 & 3.82 \\
Std. D & 1.232 & 0.877 & 0.565 & 0.716 & 0.874 \\
\hline
\end{tabular}

Note.: GCE: general comprehensive evaluation; GSE: general service evaluation; GAE: general ambience evaluation: GHE: general hygienic evaluation; GFE: general facility evaluation; Std. D: Standard Deviation.

In summary, compared with hygiene and facilities, tourists in Taiwan B\&B pay more attention to service and ambience.
Since the owners of B\&B are kind and hospitable, and usually treat tourists as friends, tourists are more satisfied with Taiwan $\mathrm{B} \& \mathrm{~B}$ service. Tourists prefer $\mathrm{B} \& \mathrm{~B}$ having quiet environment and better surrounding landscape, which can bring a sense of home. Most B\&B in Taiwan are relatively clean, but some of them have exotic smell. Generally, tourists do not pay much attention to the facilities in $\mathrm{B} \& \mathrm{~B}$, but if the facilities are not complete, it will cause dissatisfaction among the tourists.

\subsubsection{Evaluation and analysis of business site}

The research results (see Table 6) are showing that "geographical location" (70.15\%) has been mentioned most frequently in the second-grade indicators of business site. In this indicator, tourists pay high attention to "convenient transportation" (26.12\%), "distance from tourist attractions/ city center" (22.39\%) and "surroundings" (18.66\%); "Fitment" $(24.63 \%)$ and "Security" $(5.22 \%)$ in the second-grade indicators are less concerned, but it is worth noting that the "style" (16.42\%) under the "Fitment" has a high degree of attention.

Table 6. Evaluation result of "Business Site" index

\begin{tabular}{cccccc}
\hline Ind. Lv. 2 & Pct. & Ind. Lv. 3 & Pct. & Mean & Std. D. \\
\hline B1 & 70.15 & B11 & 18.66 & 4.28 & 0.678 \\
& & B12 & 26.12 & 3.83 & 1.043 \\
& & B13 & 22.39 & 4.23 & 1.006 \\
B2 & \multirow{2}{*}{24.63} & B14 & 2.99 & 3.97 & 0.879 \\
& & B21 & 8.21 & 4.36 & 0.924 \\
B3 & \multirow{2}{*}{5.22} & B32 & 16.42 & 4.32 & 0.568 \\
& & B32 & 1.49 & 4.96 & 0.108 \\
& & 3.73 & 3.40 & 1.342 \\
\hline
\end{tabular}

Note.: Ind. Lv.2: indicator level 2; Pct.: percentage; Ind. Lv.3: indicator level 3; Std. D: standard deviation.

In terms of satisfaction, the average score of each indicator is between 3.40 and 4.96. Among the eight third-grade indicators of "business site", "neighbors' attitude" (4.96) is the highest, followed by "fitment time" (4.36) and "style" (4.32), "surroundings" (4.28), "distance from tourist attractions/city center" (4.23). Relatively speaking, the satisfaction of "parking lot" (3.97), "convenient transportation" (3.83), "security management" (3.40) are lower. The inconvenient transportations are caused by far away from city center, hard to find the address, the lack of own parking spaces, the door of guestroom doesn't have double lock, service personnel enter the room at will, and insufficiently lighting in public space, etc.

To sum up, according to the evaluation index of "business site", B\&B guests are very concerned about the decoration style, the quietness of the surrounding area, the distance from the airport/ station, core tourist attractions and shopping centres, the convenience of self-driving. In Taiwan, most B\&B have kind neighbourhoods, unique decoration style, relatively quiet atmosphere, and great geographical locations. Therefore, $\mathrm{B} \& \mathrm{~B}$ guests have a wonderful living experience from these aspects.

\subsubsection{Evaluation and analysis of facilities}

The data (see Table 7) shows that in the second-grade indicators of "Facilities", tourists have more concerns in "guestroom" (51.74\%) and "electrical equipment" (21.51\%), followed by "bed" (11.63\%) and "bathroom" (9.88\%), while the attention to "entertainment" $(5.23 \%)$ is relatively low. Among the second-grade indicator of "room", "cleanliness" $(20.35 \%)$ and "area" (10.47\%) are highly concerned. Among 
the second-grade indicator of "bed", "comfortableness" $(5.81 \%)$ is highest concerned. Among the second-grade indicator of "bathroom", "facilities" (4.65\%) have the highest attention. Among the second-grade indicator of "electrical equipment", "completeness" $(13.95 \%)$ is highest concerned. Among the second-grade indicator of "entertainment", "junior rides" $(2.91 \%)$ have the highest attention.

Table 7. Evaluation results of "facilities" indicators

\begin{tabular}{cccccc}
\hline Ind. Lv. 2 & Pct. & Ind. Lv. 3 & Pct. & Mean & Std. D. \\
\hline C1 & 51.74 & C11 & 10.47 & 3.67 & 1.414 \\
& & C12 & 20.35 & 3.71 & 1.405 \\
& & C13 & 2.91 & 4.40 & 0.548 \\
& & C14 & 9.88 & 4.12 & 0.332 \\
& & C15 & 0.58 & 4.96 & 0.136 \\
C2 & \multirow{3}{*}{11.63} & C16 & 7.56 & 2.21 & 1.369 \\
& & C21 & 5.81 & 4.40 & 1.265 \\
& & C22 & 2.91 & 4.94 & 0.152 \\
C3 & \multirow{2}{*}{9.88} & C23 & 2.91 & 3.60 & 1.673 \\
& & C32 & 2.91 & 3.60 & 1.140 \\
& & C33 & 4.65 & 2.50 & 2.121 \\
C4 & \multirow{3}{*}{21.51} & C34 & 1.16 & 4.50 & 1.669 \\
& & C41 & 13.95 & 4.00 & 0.9707 \\
& & C42 & 6.40 & 2.27 & 1.191 \\
C4 & \multirow{2}{*}{5.23} & C53 & 1.16 & 3.00 & 2.828 \\
& & C52 & 1.16 & 4.03 & 0.107 \\
& & C53 & 1.16 & 4.97 & 0.130 \\
& & & 4.04 & 0.142 \\
\hline
\end{tabular}

Note.: Ind. Lv.2: indicator level 2; Pct.: percentage; Ind. Lv.3: indicator leve 3; Std. D: standard deviation.

In terms of satisfaction, "theme" (4.96), "room type" (4.40), and "decoration" (4.12) of guestrooms are highly satisfied. The satisfaction of bed is replying on the "size" (4.94) and "comfortableness" (4.40). Tourists are satisfied with "bathroom amenities" (4.50) in bathroom. And they are satisfied with "completeness" (4.00) in electrical equipment. Regarding the indicators of entertainment, "junior rides" (4.97), "Swimming pool, SPA etc." (4.04) and "tea bar" (4.03) are all satisfactory.

However, in the reviews, guests are unsatisfied with the "sound insulation" in guestroom (2.21), the "space"(2.50) and "facilities" (2.75) in bathroom, and the "performance" of electrical equipment (2.27). Specifically, poor sound insulation in guestroom, relatively small bathroom, outdated bathroom equipment (such as broken toilet, unstable hot water, etc.), poor electrical equipment (such as unstable Wi-Fi signal and TV signal, etc.).

In summary, tourists in Taiwan B\&B attach great importance to room size and sanitary conditions, but most guestrooms are not enough big and clean. Whether the completeness of electrical equipment is also highly concerned, mainly air-conditioning, Wi-Fi, TV, and elevators in some $\mathrm{B} \& \mathrm{~B}$, which brings a great convenience for tourists to carry luggage.

In addition, Taiwan's B\&B are very distinctive, which have a wide variety of room types, most of them have large and comfortable beds, good quality bathroom amenities. Some B\&B have amusement facilities specifically for children. These details are satisfied their guests.

\subsubsection{Evaluation and analysis of service}

Among the second-grade indicators of "service", compared with "personalized service" and "tourism service", B\&B guests pay the most attention to "F\&B service" (53.26\%).
Among the third-grade indicators, "breakfast service" (31.52\%), "F\&B flavour" (13.04\%) in F\&B service, and "tourism activities arrangements" (18.48\%) in tourism services catch more attention (see Table 8 ).

Table 8. Evaluation results of "service" indicators

\begin{tabular}{cccccc}
\hline Ind. Lv. 2 & Pct. & Ind. Lv. 3 & Pct. & Mean & Std. D. \\
\hline D1 & 53.26 & D11 & 31.52 & 3.86 & 1.274 \\
& & D12 & 13.04 & 4.50 & 0.905 \\
D2 & \multirow{2}{*}{22.83} & D13 & 8.70 & 4.50 & 0.535 \\
& & D21 & 4.35 & 4.25 & 0.500 \\
& D22 & 3.26 & 4.33 & 0.577 \\
& & D23 & 7.61 & 4.29 & 0.488 \\
& & D24 & 1.09 & 4.01 & 0.200 \\
D3 & & D25 & 1.09 & 4.92 & 0.109 \\
& \multirow{2}{*}{23.91} & D26 & 5.43 & 4.40 & 0.548 \\
& & D31 & 18.48 & 4.53 & 0.514 \\
& & D32 & 2.17 & 4.02 & 0.320 \\
& & D33 & 1.09 & 4.03 & 0.236 \\
& & D34 & 2.17 & 4.95 & 0.136 \\
\hline
\end{tabular}

Note.: Ind. Lv.2: indicator level 2; Pct.: percentage; Ind. Lv.3: indicator level 3; Std. D: standard deviation.

Regarding guest satisfaction, B\&B guests in Taiwan are quite satisfied with services. Except for "breakfast service" (3.86), the average scores of the remaining 12 indicators are all above 4.00. This shows that Taiwan B\&B have great performance in guest services.

To sum up, the "breakfast service" in the "F\&B service" is a basic service type of the $B \& B$, thus tourists pay more attention to this factor. If the owners haven't pay attention to details, it is easy to cause dissatisfaction among the guests. The personalized services (such as car rental, laundry, pick-up, printing, photography, etc.) and tourism services (tourism activities arrangement, valet booking, free maps and guide service, etc.) provided by B\&B owners are bonus points. These services will offer tourists a great value experience; but if not, it won't cause dissatisfaction.

\subsubsection{Evaluation and analysis of marketing}

In the second-grade indicator of "marketing" (see Table 9), guests paid more attention to "cost performance" (87.50\%) than "propaganda matches reality" $(12.50 \%)$. The cost performance in reviews is usually expressed in terms of "cost performance/ CP value". In Taiwan B\&B, tourists are not only concerned about price, but also concerned about cost performance.

Table 9. Evaluation result of "marketing" indicator

\begin{tabular}{cccc}
\hline Ind. Lv. 2 & Pct. & Mean & Std. D. \\
\hline E1 & 87.50 & 3.43 & 1.158 \\
E2 & 12.50 & 4.06 & 0.210 \\
\hline
\end{tabular}

Note.: Ind. Lv.2: indicator level 2; Pct.: percentage; Std. D: standard deviation.

\subsection{Correlation analysis}

This study uses SPSS 18.0 to analyze the relationship between three indicators of "cost performance", "number of rooms" and "latest refurbishment time" and the general quality of Taiwan B\&B through conducting a bivariate correlation analysis (see Table 10). When the significance level is 0.05 (marked as $*$ in the table) or 0.01 (marked as $* *$ in the table), the null hypothesis of the correlation coefficient test should be rejected, and it is considered that there is a linear relationship between the two indicators. The analysis results show that "cost performance" is positively correlated with "F\&B 
services" and "personalized services". "Numbers of room" is negatively correlated with "security". "Latest refurbishment time" is negatively correlated with "fitment" and "guestroom".

To draw a conclusion, (1) the higher the guestroom price of a Taiwan B\&B, the better the F\&B services quality (such as breakfast service, F\&B flavors, free meal, etc.) and personalized services (such as car rental, laundry, pick-up, printing, photography, etc.). (2) the more the guestroom numbers, the worse the security experience of $B \& B$ tourists in Taiwan; (3) the closer the B\&B refurbishment time is, tourists are more satisfied with the decoration and guestroom (such as room size, cleanliness, theme, sound insulation, etc.).

Table 10. Two-variable analysis results of sample general situation and quality evaluation

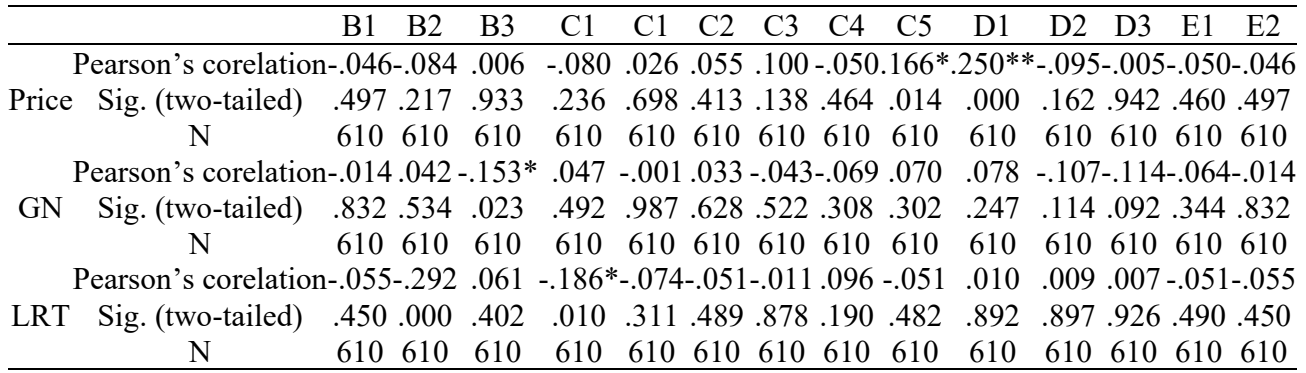

\subsection{Emotional tendency analysis}

Emotional analysis was applied to analyze the emotional words in tourist online reviews for further understanding tourists' attitude and overall impression of the B\&B. There are positive, neutral and negative emotions. The positive emotions reflect tourist's satisfaction of the $\mathrm{B} \& \mathrm{~B}$, while the negative emotions reflect dissatisfaction. The result shows what aspects of B\&B quality the tourists pay most attention to. The software of ROST Content Mining was applied for emotional tendency analysis and the result was shown in Table 11: in terms of overall impression of Taiwan $\mathrm{B} \& \mathrm{~B}$, positive emotion took highest portion, while neutral and negative emotion was much less. To be specific, most positive emotions were about convenient transport, beautiful landscape, fresh air, nice surroundings, comfortable rooms, style of the B\&B, nice owner, etc. The result of emotional tendency analysis was in line with the results of high-frequency word analysis and descriptive analysis, which proved the validity of the evaluation system of Taiwan B\&B quality.

Table 11. Guest emotional tendency analysis

\begin{tabular}{cccc}
\hline Category & Pct. & Strength & Pct. \\
\hline & & low & 8.8 \\
Positive emotion & 81.2 & medium & 22.3 \\
& & high & 50.1 \\
Neutral emotion & 12.2 & $/$ & 12.2 \\
& & low & 4.12 \\
Negative emotion & 6.6 & medium & 1.45 \\
& & high & 1.03 \\
Total & 100 & & 100 \\
\hline
\end{tabular}

\section{CONCLUSION AND IMPLICATION}

\subsection{Conclusion}

Based on the online guest reviews of Taiwan B\&B on Agoda, this study is applying content analysis to analyze the quality of Taiwan B\&B. Findings are as below:

Firstly, tourists are more concerned about the ambience and service experience of Taiwan B\&B, they prefer B\&B which are quiet and having better surrounding landscapes. Since Taiwan B\&B owners are usually kind, hospitable, warm and considerate, they can make tourists feel at room. On the whole, tourists are satisfied with Taiwan B\&B.

Secondly, Taiwan B\&B quality evaluation index system set first grade indicators: "business site", "facilities", "service" and "marketing". (1) In terms of "business site", B\&B guests attach a great importance to the quietness of the surrounding environment, the distance from the airport/station, core tourist attractions and shopping centers, and the decoration style. Taiwan B\&B could provide guests with a better accommodation experience in these aspects; (2) In terms of "facilities ", tourists attach great importance to the size and sanitation of guestroom, and whether the electrical equipment is complete. In fact, the size and sanitation of Taiwan's B\&B guestrooms cannot be adequate; but most B\&B have airconditioning, WI-FI, TV, and even elevators, which brings a better stay experience to tourists. In addition, the rooms of Taiwan B\&B are very distinctive, with a wide range of room types, large and comfortable beds, good quality bathroom amenities, and some B\&B have special amusement facilities for children. These aspects satisfied B\&B tourists; (3) In terms of service, "breakfast service" is the most important factor, which most likely to cause dissatisfaction among tourists. The personalized services (such as car rental, laundry, pick-up, printing, photography, etc.) and tourism services (route or activity arrangements, booking tickets for attractions, free maps and explanations, etc.) provided by $\mathrm{B} \& \mathrm{~B}$ owner are the shining point of the B\&B services; (4) in terms of "marketing", travelers will pay attention to whether the photos on the website are consistent with the actual situation. But more important is the cost performance; travelers will not care too much about the price, but they want to get the quality of accommodation that matches the price.

Thirdly, the correlation analysis shows that the price of Taiwan B\&B is positively correlated with the $\mathrm{F} \& \mathrm{~B}$ services (such as breakfast service, catering taste, free meal service, etc.) and personalized services (such as car rental, laundry, pick-up, printing, photography, etc.); the number of $\mathrm{B} \& \mathrm{~B}$ guestrooms in Taiwan is negatively correlated with the security during stay; $\mathrm{B} \& \mathrm{~B}$ refurbishment time is positively correlated with the decoration style and interior of the guestroom (such as room size, cleanliness, theme type, sound insulation, etc.).

\subsection{Enlightenment}

The evaluation results of Taiwan B\&B quality have certain guiding significance in the mainland of China. 


\subsubsection{Pay attention to the location of $B \& B$}

According to the findings of this article, site selection is one of the key success factors of Taiwan B\&B. The location of $\mathrm{B} \& \mathrm{~B}$ should focus on the following two factors: surrounding environment and traffic conditions, such as convenient transportation, quiet environment, nearby scenic spots, leisure blocks or surrounding landscape.

\subsubsection{Improve B\&B services}

The considerate service is the core competitiveness of $B \& B$. Basic service, such as sanitary cleaning, timely feedback on guest requirements, breakfast service and so on, is the base of lodging industry; once it doesn't meet the guests' psychological expectations, the evaluation of $B \& B$ will be declined. Followed by value-added services. Such as bicycle or battery car rental, photo printing, machine laundry, airport/station free shuttle and other personalized services, and help guests book tickets for sightseeing projects, professional tourism guidance (such as arranging tourist routes, interpretation, experience projects guide, etc.), free local maps and other tourism services. Missing those services won't lower the evaluation of the $\mathrm{B} \& \mathrm{~B}$, but if available, which will have a significant improvement in guest satisfaction.

\subsubsection{Improve the staying experience}

B\&B was originally a supplementary form of the lodging industry; nowadays, $\mathrm{B} \& \mathrm{~B}$ have become an important component of non-standard accommodation. Therefore, the most important experience that $\mathrm{B} \& \mathrm{~B}$ brings to tourists is accommodation experience, because actually most of the time guests are spent in the room. In order to offer guests a better staying experience, B\&B needs to set sound insulation, comfort bed and bedding, clean bath, delicate decoration, and useful equipment (such as WI-FI, TV, air-conditioning). In terms of convenience and effect, the materials and designs are carefully selected, so that guests could have wonderful experience. The space outside guestrooms, such as tearoom, book cafe, junior rides, swimming pool or SPA, is the plus of the hotel.

\subsubsection{Highlight the culture of host}

During the evaluation of Taiwan B\&B, "feeling at home" appears very frequently. The feeling of home is not determined by the internal and external hardware conditions of $\mathrm{B} \& \mathrm{~B}$; but is formed by the care and companionship of the $\mathrm{B} \& \mathrm{~B}$ host. This is the true meaning of "people" in the B\&B. Therefore, the host of $\mathrm{B} \& \mathrm{~B}$ must have a clear self-positioning; they are not simple waiters, but tutors who can help guests truly understand this B\&B and the local area (including landscape, humanities, specialties, crafts, etc.) Through the communication between the traveler and the host, the traveler can deeply understand local culture and the spirits of this B\&B, and even form a spiritual resonance with the host. "Relationship" is the key factor in revisiting the B\&B.

\section{REFERENCES}

[1] Hong, L.Z. (2009). Research on the forecast of taiwan's homestay industry development. Journal of Business Modern Chemistry, 5(1): 183-198. https://doi.org/19918577-200903-201003310099201003310099-183-198
[2] Li, P.P., Shan, W.J. (2017). Research on the status quo and improvement strategies of the quality of homestays around Hangzhou West Lake scenic area based on content analysis method. Modern Business, (18): 28-30. http://dx.doi.org/10.14097/j.cnki.5392/2017.18.012

[3] Guo, C.M., Wu, C.F., Wu, Z.J., Yang, J.R., Cai, Y.J., Cai, Z.L. (2012). Research on the difference in service quality perception between homestay industry and consumers: a case of Xinshe area, Leisure and Tourism Industry Research, 6(1): 66-79. http://dx.doi.org/10.6158/JLTIR.201205_6(1).0005

[4] Su, L.M., Wang, C.H. (2015). Using customer value map to explore the service quality of Taiwan's hospitality industry. Interdisciplinary Integrated Management Seminar, Taiwan, 604-617. http://dx.doi.org/10.18686/bd.v2i9.1657

[5] Zhuang, W.L., Lin Z.L. (2013). Research on the impact of the service quality of the homestay industry on the willingness of tourists to stay again. Jiada Sports, Health and Leisure Journal, (3): 78-88. http://dx.doi.org/10.6169/ NCYUJPEHR.12.3.08

[6] Chuang, C.A., Lin, S.C., Wu, T.C. (2012). A study on word-of-mouth communication in bed and breakfast: the relationships among interaction quality and satisfaction. Journal of Hospitality and Tourism, 9(3): 133-149. http://dx.doi.org/10.6572\%2fJHT.9(3).2

[7] Chen, H.L., Wu, Y.G. (2009). Research on the relationship between tourists' service quality and recreational experience in homestays: A case of Wutai Homestay in Pingtung. Marketing Review, 6(2): 299-327. http://dx. doi.org/10.29931/MR.200906.0005

[8] Chen, R.L. (2011). Research on the service quality, shopping value and behavior intention of homestay. Leisure and Health Care Journal, (5): 45-54. http://dx.doi.org/10.29931/MR.200906.0005

[9] Zheng, J.X. (1998). Research on the corporate management strategy of Taiwan's leisure farms. Unpublished doctoral dissertation, National Taiwan University, Taiwan, China. http://doi.org/10.19765/j.cnki.1002-5006.2019.01.014

[10] Wu, L.K., Tao, Y.G. (2016). The development of Taiwan $\mathrm{B} \& \mathrm{~b}$ industry and its englightment on countryside tourism of mainland. Journal of Jiangsu Normal University (Philosopy and Social Sciences Edition), 42(2): 154-158. http://doi.org/10.16095/j.cnki.cn321833/c.2016.02.022

[11] Chen, M., Qi, Y.B., Liu, H.X. (2014). The Enlightment of Taiwan B\&B to the Development of B\&B industry in Mainland of China. City Tourism Plan, 10(2): 274-276. http://doi.org/10.27155/d.cnki.ghqiu.2019.000045

[12] Wang, J.Y. (2017). Research on online short-term rental service quality evaluation based on network text analysis: A case of Tujia self-operated apartment. Tourism Forum, 10(1): 73-88. http://doi.org/10.15962/j.cnki.201701008

[13] Xiang, Z., Gretzel, U. (2010). Role of social media online travel information search. Tourism Management, 31(2): 179-1188. https://doi.org/10.1016/j.tourman.2009.02.016

[14] Zhan, Y.Y., Wang, Z.X. (2017). Research on the quality, satisfaction and loyalty of online booking websites: Taking Agoda as an example. Leisure \& Holistic Wellness, (5): 45-66. http://dx.doi.org/10.29686/LHW.201106.0005 